www.ijpsonline.com

\title{
Combined Therapy with Insulin and Vildagliptin causes Cardiac Dysfunction in Diabetic Rats
}

\author{
PRIYA EBENESAN* AND MALLIKA JAINU ${ }^{1}$ \\ Department of Biochemistry, Research and Development Centre, Bharathiar University, Coimbatore-641 046, ${ }^{1}$ Department of \\ Biomedical Engineering, Sri Siva Subramaniya Nadar College of Engineering, Kalavakkam, Chennai-603 110, India
}

Ebenesan and Jainu: Cardiac Dysfunction in Diabetic Rats on Combination Therapy

\begin{abstract}
There is a strong rationale for using incretin-based therapies with insulin. In particular, hypoglycaemia is the limiting factor in glycemic management of insulin-treated patients of type 2 diabetes mellitus. The present study aimed at gaining greater understanding of the progression of cardiovascular degeneration in diabetes mellitus under combined treatment with vildagliptin and insulin through various analyses on cardiac tissues such as triphenyl tetrazolium chloride dye test. Experimental diabetic rats exhibited significantly lower TCA cycle enzyme and antioxidant defence enzyme activities with a concomitant increase in lipid peroxidation of the heart tissue. Monotherapy with either vildagliptin or insulin prevented these alterations in the oxidative energy metabolism and restored the TCA cycle enzyme activities to near normal in alloxan diabetic rats whereas the combined therapy altered mitochondrial enzyme levels significantly. These findings suggested that the toxic effects of the combinatorial therapy could be attributed to an increased oxidative damage and altered mitochondrial energy production, which might lead to progression of cardiovascular disease.
\end{abstract}

Key words: Diabetes mellitus, insulin, vildagliptin, cardiac mitochondria, antioxidants, incretin

Adverse drug reaction (ADR) usually occurs with the long term use of a drug or sudden stoppage of drug use. Drug approval is given after many clinical trials but once they reach the market, only doctors can monitor these $\mathrm{e}^{[1]}$.

Metformin monotherapy has been the initial treatment option for type 2 diabetes but as it produced a wide range of ADRs and difficulties to sustain glycemic control, combination therapy with drugs with complementary mechanism of action has become the main stay in the management of diabetes. Metformin is combined with other oral antidiabetic agents like thiazolidinediones, acarbose or insulin. Since metformin lowers plasma glucose without affecting insulin secretion it has been combined with sulphonylureas but as this combination substantially increased risk of hypoglycaemia, it became necessary to combine with more glucose sensitive agents, which resulted in a combination of dipeptidyl peptidase-4 (DPP-4) inhibitors together with insulin. Incretins are intestinal hormones secreted in response to ingestion of food through the gut, which in turn would increase glucose levels in the blood and enhance insulin secretion ${ }^{[2]}$. Vildagliptin, a DPP4 inhibitor, enhances secretion of insulin and reduces blood glucose levels.

*Address for correspondence

E-mail: priya_28122003@yahoo.co.in
The cardiovascular system (CVS) controls the entire blood supply for the effective functioning of the body. When the CVS suffers degeneration, it leads to many complications, of which those occurring with a prevailing diabetic condition have been most widespread in India ${ }^{[3]}$. Reduction in the level of mitochondrial enzymes would lead to increase in the level of nicotinamide adenine dinucleotide phosphate hydrogen (NADPH) and other reactive oxygen species (ROS), which in turn will lead to cardiac tissue damage. Our findings demonstrated that insulin and vildagliptin downregulated levels of cardioprotective proteins in the myocardium suggest a possible role of GLP-1 in the context of decreased survival rate of rats.

Adult male Wistar rats weighing 150-200 g were used in the present investigation. Rats were housed in clean polypropylene cages and maintained under standard conditions (temperature $25 \pm 2^{\circ}$ with dark/ light cycle 12/12h). Rats were fed with standard pellet

This is an open access article distributed under the terms of the Creative Commons Attribution-NonCommercial-ShareAlike 3.0 License, which allows others to remix, tweak, and build upon the work non-commercially, as long as the author is credited and the new creations are licensed under the identical terms

Accepted 17 April 2018

Revised 12 September 2017

Received 17 January 2017 Indian J Pharm Sci 2018;80(3):575-580 
diet (Hindustan Unilever, Kolkata, India) and water ad libitum. All procedures described were reviewed and approved by the Institutional Animal Ethics Committee, (IAEC No/03/006/2014). Diabetes was induced with a single dose $(150 \mathrm{mg} / \mathrm{kg}$; i.p. $)$ of freshly prepared solution of alloxan monohydrate in normal saline in $18 \mathrm{~h}$ fasted rats. Hyperglycemia was confirmed by elevated glucose level in plasma determined at $48 \mathrm{~h}$ after injection. Rats with blood glucose levels above $250 \mathrm{mg} / \mathrm{dl}$ were considered diabetic and selected for the study.

Rats were divided into 5 groups consisting of 6 animals in each group. Group I rats received normal saline $(1 \mathrm{ml} / \mathrm{kg})$ and group II rats were administered with alloxan $(150 \mathrm{mg} / \mathrm{kg} / \mathrm{d})$ intraperitoneally as a single dose to induce diabetes ${ }^{[4]}$. Group III diabetic rats were treated with vildagliptin $(0.69 \mathrm{mg} / \mathrm{kg})$ given orally as a single dose for $10 \mathrm{~d}^{[5]}$. Group IV diabetic rats were treated with insulin $(0.27 \mathrm{IU} / \mathrm{kg})$ administered intramuscularly as a single dose for $10 \mathrm{~d}^{[6]}$. Group $\mathrm{V}$ diabetic rats were treated with insulin $(0.27 \mathrm{IU} / \mathrm{kg})$ and vildagliptin $(0.69 \mathrm{mg} / \mathrm{kg})$ for $10 \mathrm{~d}$. Animals were sacrificed by injecting sodium pentobarbitone and blood was collected in plain and heparinized tubes immediately after the sacrifice. Blood samples were centrifuged for $10 \mathrm{~min}$ at $2500 \mathrm{rpm}$, the serum separated has been stored at $4^{\circ}$ until further investigations. Heart tissue was dissected out immediately and washed in ice-cold saline. Mitochondria were isolated according to the method of Johnson and Lardy ${ }^{[7]}$. Heart tissue was homogenised in ice-cold sucrose $(0.25 \mathrm{M})$ and the homogenate was centrifuged at $600 \times \mathrm{g}$ for $10 \mathrm{~min}$. The supernatant was then centrifuged in a refrigerated Beckman J2-21 centrifuge at $10000 \times \mathrm{g}$ for $5 \mathrm{~min}$. The pellet was taken and the supernatant was discarded.

The mitochondrial pellet was suspended in $0.25 \mathrm{M}$ sucrose containing $10 \mathrm{mM}$ Tris- $\mathrm{HCl}(\mathrm{pH}$ 7.4) and $1 \mathrm{mM}$ EDTA to a known volume $(2 \mathrm{ml})$ and used for the following enzyme estimations. Thiobarbituric acid reactive substance (TBARS) was estimated according to the method of Tsai and Huang ${ }^{[8]}$, superoxide dismutase (SOD) $)^{[9]}$, catalase (CAT) using the method of Sinha ${ }^{[10]}$, glutathione peroxidase $(\mathrm{GPx})^{[11]}$, glutathione reductase (GR) as per the method reported by Manervik ${ }^{[12]}$, and glutathione $(\mathrm{GSH})^{[13]}$ was assayed in tissue homogenate. The activities of isocitrate dehydrogenase $(\mathrm{ICDH})^{[14]}, \alpha$-ketoglutarate dehydrogenase $(\alpha-\mathrm{KGDH})^{[15]}$, succinate dehydrogenase $(\mathrm{SDH})^{[16]}$, malate dehydrogenase $(\mathrm{MDH})^{[17]}$ and NADH dehydrogenase ${ }^{[18,19]}$ were estimated. Mitochondrial protein content was estimated using the method of Lie et al. ${ }^{[20]}$.

Triphenyltetrazolium chloride (TTC) test was used for the macroscopic enzyme mapping assay of the ischemic myocardium according to the method of Lie et al. ${ }^{[20]}$. The heart was washed rapidly in cold buffer to remove excess blood, taking care not to macerate the tissue. The excess epicardial fat was lightly trimmed off and the left ventricle was separated. The heart was transversely cut across the left ventricle to obtain slices no more than $0.1 \mathrm{~cm}$ in thickness. The heart slices were placed in a covered, darkened glass dish containing prewarmed $1 \%$ TTC solution in phosphate buffer and the dish was put in an incubator heated between 37 and $40^{\circ}$ for $30-45 \mathrm{~min}$. The heart slices were turned over once or twice to make certain that it remained immersed and covered by $1 \mathrm{~cm}$ of the TTC solution. At the end of the incubation period, the heart slice was placed in a fixing solution, which not only fixed the tissue but also enhanced the colour contrast developed. Photographs were taken using 16x mega pixel digital camera at 1 feet distances for all the groups. Briefly, digital images of 5 slices in each heart were analysed using the NIH ImageJ 1.4 software. Heart damage was expressed as the ratio of the infarcted area (white area in the right side) to the area of the undamaged, contralateral hemisphere.

Results were expressed as mean \pm SEM. Statistical significance was determined by one-way analysis of variance (ANOVA) and Dunnett's post hoc test. For data processing SPSS data analysis software version 21.0 was used. The study revealed increased endogenous lipid peroxidation and decreased antioxidant enzyme activities in the heart as assessed by the analyses of SOD, CAT, GPx and GR in alloxan diabetic rats and the mild but significant decrease of these activities and significant increase in the levels of TBARS were noted in rats treated with a combination of vildagliptin and insulin. The levels were restored to normal in monotherapy conditions even in alloxan diabetic rats (figs. 1A-C and 2).

The alteration in the activities of $\mathrm{ICDH}, \mathrm{MDH}, \mathrm{SDH}$ and $\alpha-\mathrm{KGDH}$ observed in alloxan diabetic rats was significant when vildagliptin or insulin was given as a monotherapy, however, there was a moderate increase when insulin was given as a monotherapy, whereas when insulin and vildagliptin were given in combination, a significant reduction was observed in the activity of 

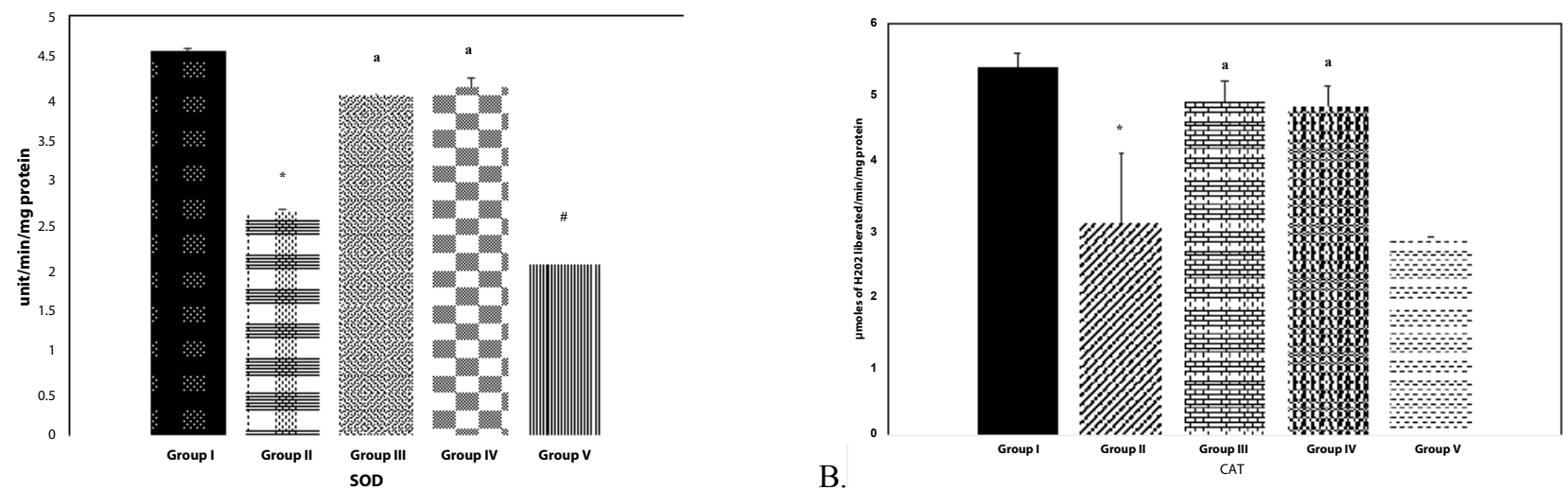

\section{A.}

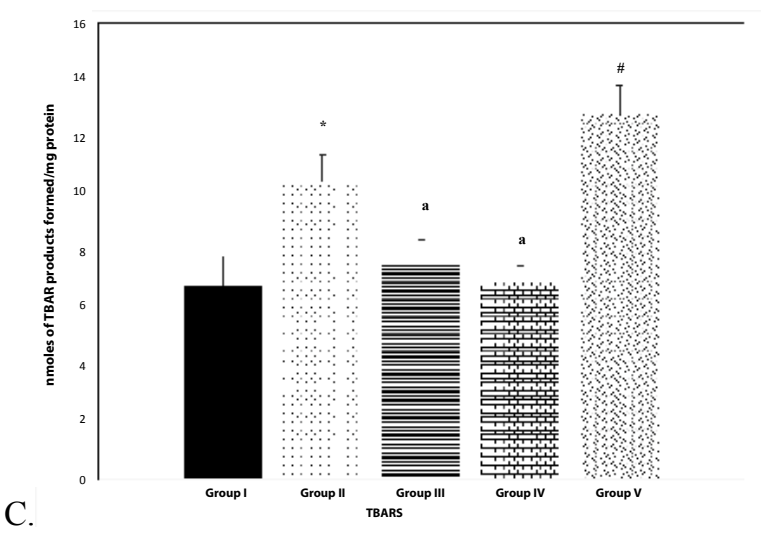

Fig. 1: Effect of vildagliptin and insulin on antioxidant levels in cardiac tissues of diabetic rats

Effect of vildagliptin and insulin on (A) superoxide dismutase, (B) catalase enzyme activities and (C) TBARS level in the cardiac tissue of diabetic rats. Results are expressed as mean $\pm S E M, n=6$. " $P<0.01$, statistically significant as compared with normal control rats; ${ }^{a} \mathbf{p}<0.01$, statistically significant as compared with diabetic rats and ${ }^{\#} p<0.01$, statistically significant as compared with normal

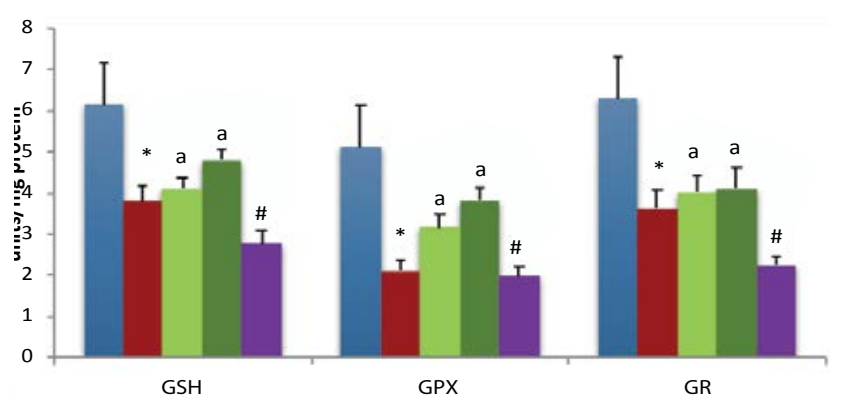

Fig. 2: Effect of vildagliptin and insulin on glutathione system in cardiac tissue of diabetic rats

Effect of vildagliptin and insulin on glutathione, glutathione peroxidase and glutathione reductase enzyme activities in cardiac tissue of diabetic rats. Results are expressed as mean \pm SEM, $n=6$. ${ }^{*} P<0.01$, statistically significant as compared with normal control rats; ${ }^{a} \mathbf{p}<0.01$, statistically significant as compared with diabetic rats, ${ }^{\#} \mathbf{p}<0.01$, statistically significant as compared with normal. GPX- $\mu \mathrm{g}$ of GSH consumed/ $\mathrm{min} / \mathrm{mg}$ protein; GR- $\mu$ moles of NADPH oxidized/min $/ \mathrm{mg}$ protein; GSH- nmoles/g wet tissue. " Group I; " group II; group III; $₫$ group IV; $₫ \operatorname{group~V}$

these enzymes and a simultaneous reduced production of ATP to a level similar to that seen in untreated diabetic rats and this could be due to severity of cardiac damage occurred during combination therapy (figs. 3, $4 \mathrm{~A}$ and $\mathrm{B})$.

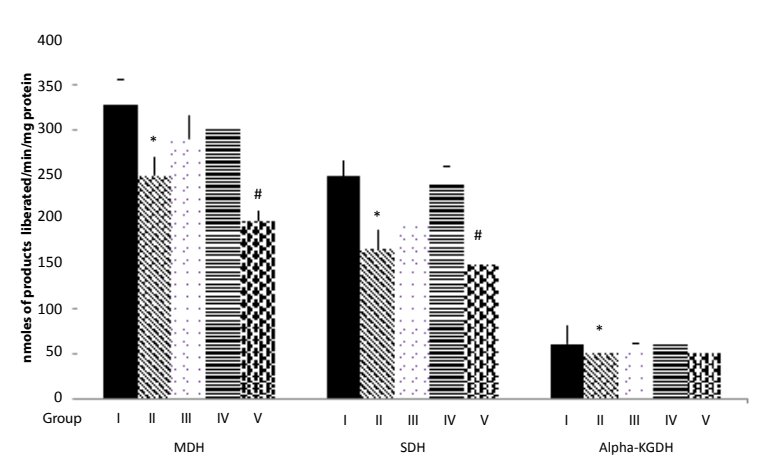

Fig. 3: Effect of vildagliptin and insulin on various dehydrogenase enzyme activities in cardiac tissue of diabetic rats

Effect of vildagliptin and insulin on succinate dehydrogenase, malate dehydrogenase and $\alpha$-ketoglutarate dehydrogenase activities in cardiac tissues of diabetic rats. Results are expressed as mean \pm SEM, $n=6$. ${ }^{*} P<0.01$, statistically significant as compared with normal control rats; ${ }^{\mathrm{a}} \mathrm{p}<0.01$, statistically significant as compared with diabetic rats; ${ }^{\#} p<0.01$, statistically significant as compared with normal group. SDH- nmoles of succinate oxidized/min/mg protein; MDH- nmoles of NADH oxidized/min/mg protein; $\alpha$-KGDH- nmoles of potassium ferrocyanide liberated $/ \mathrm{min} / \mathrm{mg}$ protein

In control rats (fig. 5A) the cardiac tissue was bright red in colour with increased enzyme levels of SDH indicated that the tissues were healthy. In the diabetic 
control (fig. 5B), the cardiac tissue was light pale red to greyish-yellow in colour indicating that the enzyme levels have reduced due to ischemia. In fig. $5 \mathrm{C}$, vildagliptin monotherapy there was a pale grey coating on the ventricular part and it appeared dull red in colour showing that there was revival of cardiac tissue to some extent. In the fig. 5D, when insulin was given as a monotherapy the tissues appeared pale red in colour. Fig. 5E showed uncoloured fibrous scars turned to white ischemic myocardium, which clearly showed that during the combination therapy, the cardiac tissue was damaged and it had led to mitochondrial dysfunction with alteration of enzymes like SDH activities. The quantification of ischemic area in TTC mapping image showed in the fig. 6 .

Oxidative damage to the biomolecules increases with the age and it is a major factor for degenerative disorders. Oxidative stress is a condition in which there is an increased production of free radicals and other lipid peroxidation products. This in turn will lead to the oxidant related reactions and cellular and organ damage ${ }^{[21]}$.

Diabetes is induced by alloxan by increased intracellular generation of ROS and together with the reduced product of alloxan, dialuric acid, which will cause inhibition of secretion of insulin. The imbalance between the level of ROS and the level of antioxidants in the body may lead to the oxidative stress which in turn will lead to tissue damage ${ }^{[22]}$. The level of TBARS has been significantly increased in the combinatorial therapy showing that there is a free radical production leading to ischemia. Mitochondrial superoxide overproduction takes place in diabetes, which in turn will lead to tissue damage as reported in earlier studies ${ }^{[23]}$. Normal cardiac functioning can be accomplished by supply of energy by cardiac mitochondria. The mitochondrial dysfunction is responsible for insulin resistance that takes place in various tissues including myocardial tissues ${ }^{[24,25]}$.

The activities of various citric acid cycle enzymes like ICDH, $\alpha-\mathrm{KGDH}, \mathrm{SDH}, \mathrm{MDH}$ and NADH dehydrogenase decreased in the experimentally induced diabetic rats, which was similar to what was reported earlier ${ }^{[26]}$. The alterations were restored back to normal level when vildagliptin was given as a monotherapy and there was a moderate increase in the cardiac energy level of the rats when insulin was given as a monotherapy. Whereas combination therapy reduced the levels of these enzymes and lowered ATP production to levels found under diabetic condition due
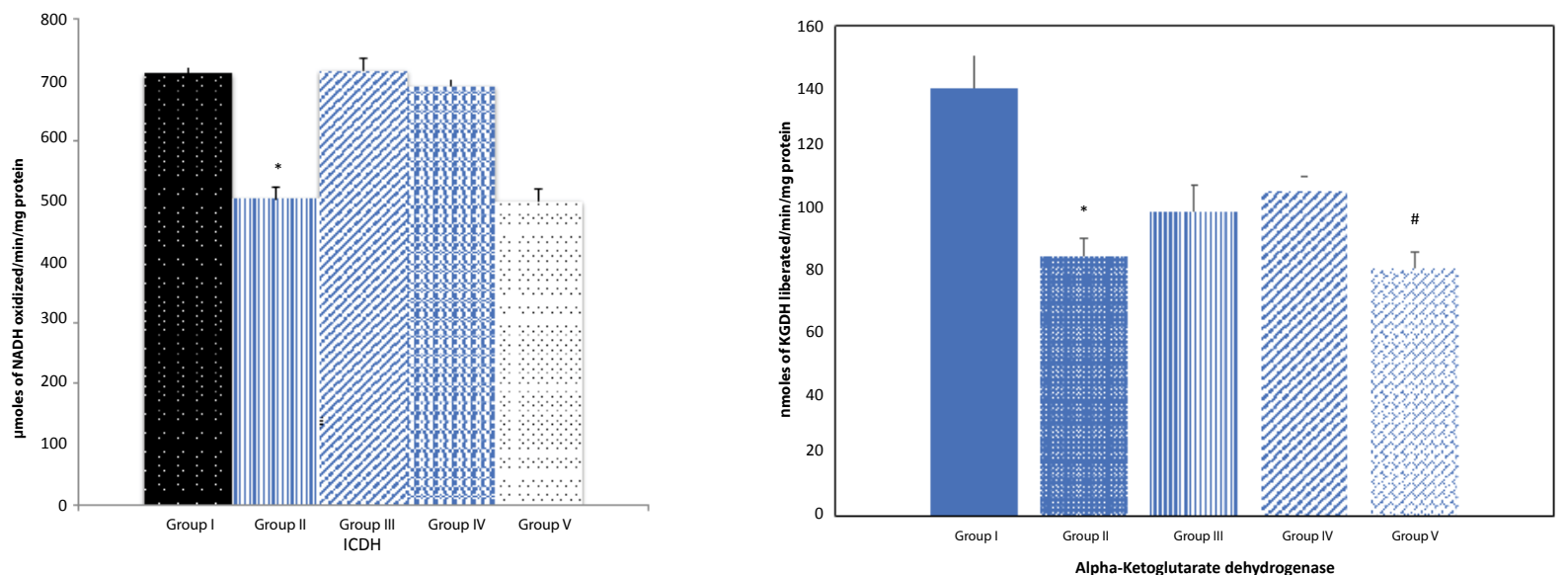

Fig. 4: Effect of vildagliptin and insulin on isocitrate dehydrogenase and NADP dehydrogenase enzyme activities in cardiac tissue of diabetic rats

Results are expressed as mean \pm SEM, $n=6$. ${ }^{*} P<0.01$, statistically significant as compared with normal control rats; ${ }^{a} p<0.01$, statistically significant as compared with diabetic rats; ${ }^{\sharp} p<0.01$, statistically significant as compared with normal
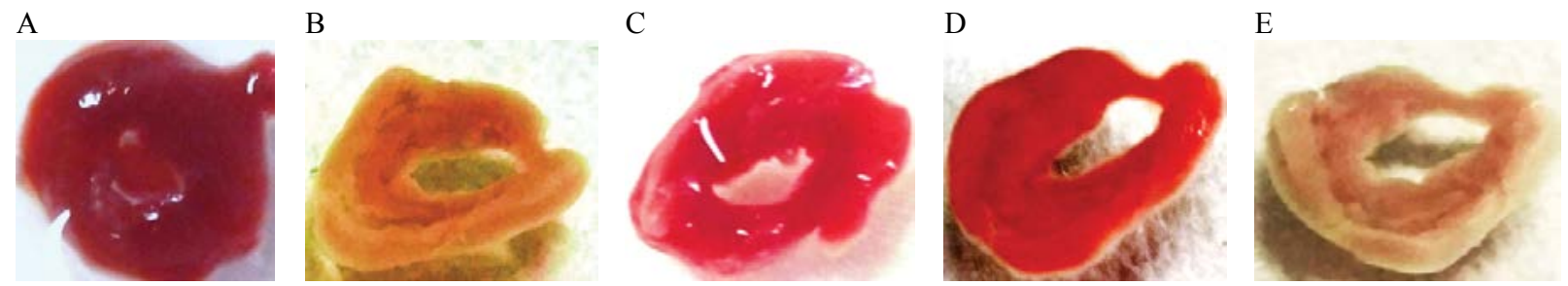

Fig. 5: Triphenyltetrazolium chloride dye test in cardiac tissue

A- Normal control; B- diabetic control; C- diabetic+vildagliptin; D- diabetic+insulin; E- diabetic+insulin+vildagliptin 


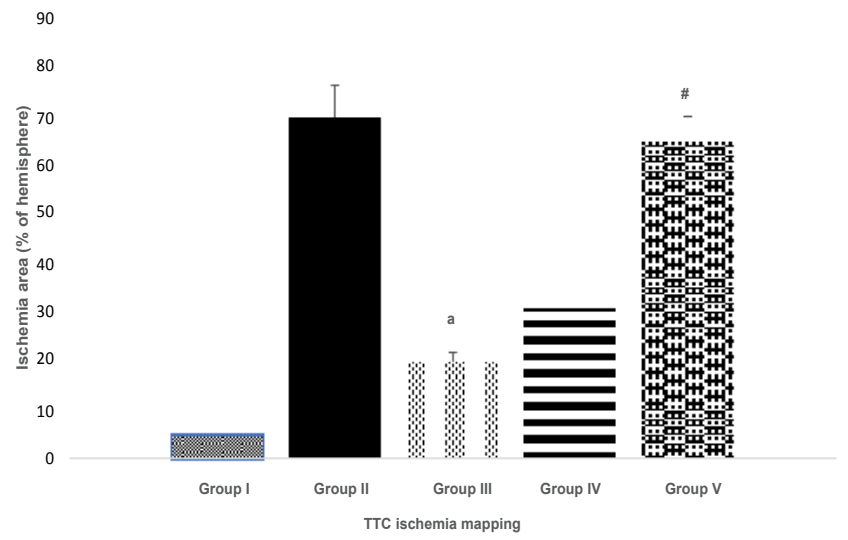

Fig. 6: Quantification of in vivo TTC-labeling in experimental cardiac injury models

Results are expressed as mean $\pm \operatorname{SEM}, n=6$. ${ }^{*} P<0.01$, statistically significant as compared with normal rats; ${ }^{\#} p<0.01{ }^{a} p<0.01$, statistically significant as compared with diabetic rats; ${ }^{\#} \mathbf{p}<0.01$, statistically significant as compared with normal

possibly to cardiac damage induced by the combination therapy.

NADPH is required for the antioxidant system for the proper functioning of the three major components, the GSH system, CAT and SOD ${ }^{[27]}$. The four enzymes involved in the production of NADPH in mammalian cells are glucose-6-phosphate dehydrogenase (G6PD), phosphoglycerate dehydrogenase, malic enzyme and ICDH. G6PD utilizes NADPH for many cellular activities and if it is inhibited the other processes requiring NADPH will be affected. Other enzymes in the body do not provide sufficient amount of NADPH required for the cellular activities. Impaired myocardial energy production will lead to decreased cardiac contractility and NAPH. Diabetic state in rats causes inhibition of respiratory chain activity leading to increased ROS production, which, in turn, impairs the mitochondrial protein import machinery, alteration of mitochondrial enzymes, assembly of respiratory chain complexes, and mPTP opening. This further exacerbates cellular oxidative stress and promotes cardiac damage.

Mitochondrial calcium regulation was totally impaired because of lack of sufficient energy, which in turn leads to cardiac dysfunction during combination therapy ${ }^{[28]}$. The oxidative stress is mostly regulated by AMP activated protein kinase in the endothelial cells. Reduction in the concentration of antioxidant enzymes took place during combination therapy of vildagliptin and insulin leading to delay in tissue repair. Decreased production of energy also led to an impaired mitochondrial calcium handling, which might have caused cardiac dysfunction. There is increasing evidence from preclinical and clinical studies supporting the adverse effects of vildagliptin and insulin therapy, for example as secondary findings, it has been found that there was lower diastolic and systolic blood pressure with a slightly higher heart rate after vildagliptin treatment ${ }^{[29,30]}$. In another study, higher mortality rate was observed in the intensive treatment group, which failed to report significant reduction in major cardiovascular events, giving a notion that intensive therapy was associated with significant harm in high-risk patients ${ }^{[31]}$.

Findings of this investigation indicated that insulin and vildagliptin combined therapy downregulated the cardiac tissue antioxidants and mitochondrial enzyme activities in the ischemic myocardium, which suggested the negative role of this combination in diabetic condition.

\section{Conflicts of interest:}

The authors declare that there are no conflicts of interest.

\section{Financial support and sponsorship:}

Nil.

\section{REFERENCES}

1. Rabbur RSM, Emmerton L. An introduction to adverse drug reaction reporting system in different countries. Int $\mathrm{J}$ Pharm Pract 2005;13:91-100.

2. Baggio LL, Drucker DJ. Biology of incretins: GLP-1 and GIP. Gastroenterology 2007;132:2131-57.

3. El-Ouaghlidi A, Rehring E, Schweizer A, Holmes D, Nauck MA. The dipeptidyl peptidase IV inhibitor LAF237 does not accentuate reactive hypoglycemia caused by the sulfonylurea glibenclamide administered before an oral glucose load in healthy subjects. Diabetes 2003;52:118.

4. Shekha MS. The effects of rhubarb root and antihyperlipidemic drug on some physiological parameters in male rats. J Dohuk Univ 2008;11:136-43.

5. Rodriguez R, Viscarra JA, Minas JN, Nakano D, Nishiyama A, Ortiz RM, et al. Angiotensin receptor blockade increases pancreatic insulin secretion and decreases glucose intolerance during glucose supplementation in a model of metabolic syndrome. Endocrinology 2012;153:1684-95.

6. Burkey BF, Li X, Bolognese L, Balkan B, Mone M, Russell M., et al. Acute and chronic effects of the incretin enhancer vildagliptin in insulin-resistant rats. J Pharmacol Exp Ther 2005;315:688-95.

7. Johnson D, Lardy HA. Isolation of Liver and Kidney Mitochondria. Methods Enzymol 1967;10:94-6.

8. Tsai MC, Huang TL. Thiobarbituric acid reactive substances (TBARS) are a state biomarker of oxidative stress in bipolar patients in a manic phase. J Affect Disord 2015;173:22-6.

9. Misra HP, Fridovich I. The role of superoxide anion in the 
autooxidation of epinephrine and a simple assay for superoxide dismutase. J Biol Chem 1972;247:3170-75.

10. Sinha AK. Colorimetric assay of catalase. Anal Biochem 1972;47:389-94.

11. Rotruck JT, Pope AL, Ganther H, Awanson AB, Hafeman DG, Hoeckstra WG, et al. Selenium biochemical role as component of glutathione peroxidase. Science 1973;179:588-89.

12. Manervik CB. Glutathione levels in rat brain. J Biol Chem 1975;250:5475-80.

13. Beutler E, Duron O, Kelly BM. Improved method for the determination of blood glutathione. J Lab Clin Med 1973;61:882-88.

14. Bell AJL, Baron DN. A colorimetric method for determination of isocitrate dehydrogenase. Clin Chim Acta 1960;5:740-47.

15. Reed LJ, Mukherjee RB. $\alpha$-ketoglutarate dehydrogenase complex from Escherichia coli. In: Lewinstein JM, editors. Methods in Enzymology. New York. Academic Press 1969. p. 55-61.

16. Slater ECC, Bonner WD. The effect of fluoride on succinic oxidase system. Biochem J 1952;52:185-96.

17. Mehler AH, Konberg A, Criscolin S, Ochon S. The enzymatic mechanism of oxidation-reductions between malate or isocitrate or pyruvate. J Biol Chem 1948;174:961-77.

18. Minakami S, Ringler RL, Singer JP. Studies on the respiratory chain linked dihydrodiphosphopyridine nucleotide dehydrogenase. I. Assay of the enzyme in particulate and in soluble preparations. J Biol Chem 1962;237:569-76.

19. Lowry OH, Rose Borough MJ, Farr AL, Randall RJ. Protein measurement with the folin phenol reagent. J Biol Chem 1951;193:265-75.

20. Lie JT, Pairolero PC, Holley KE, Titus JL. Macroscopic enzyme-mapping verification of large, homogenous, experimental myocardial infarcts of predictable size and location in dogs. J Thorac Cardiovasc Surg 1975;69:599-605.
21. Sies H. Oxidative stress: oxidants and antioxidants. Exp Physiol 1997;82:291-95.

22. Furukawa S, Fujita T, Shimabukuro M, Iwaki M, Yamada $\mathrm{Y}$, Nakajima Y, et al. Increased oxidative stress in obesity and its impact on metabolic syndrome. J Clin Invest 2004;114:1752-61.

23. Ravassa S, Zudaire A, Diez J. GLP-1 and cardioprotection: from bench to bedside. Cardiovasc Res 2012;94:316-23.

24. Michael H, Martin F, Standl E. Vildagliptin-An oral dipeptidyl peptidase-4 inhibitor for type 2 diabetes. US Endocrinol 2006;2:75-81.

25. Panneerselvam RS, Govindaswamy S. Effect of Sodium molybdate on carbohydrate metabolizing enzymes in alloxaninduced diabetic rats. J Nutr Biochem 2002;13:21-6.

26. Balaban RS. Cardiac energy metabolism homeostasis: role of cytosolic calcium. J Mol Cell Cardiol 2002;34:1259-71.

27. Zhang Z, Liew CW, Handy DE, Zhang Y, Leopold JA, Hu J, et al. High glucose inhibits glucose-6-phosphatedehydrogenase, leading to increased oxidative stress and $\beta$-cell apoptosis. FASEB J 2010;24:1497-505.

28. Fisslthaler B, Fleming I. Activation and signalling by the AMP-activated protein kinase in endothelial cells. Circ Res 2009;105:114-27.

29. Wilkinson IB, Webb DJ. Venous occlusion plethysmography in cardiovascular research: methodology and clinical applications. Br J Clin Pharmacol 2001;52:631-46.

30. Amori R, Lau J, Pittas A. Efficacy and safety of incretin therapy in type 2 diabetes: systematic review and metaanalysis. JAMA 2007;298:194-206.

31. Gerstein HC, Miller ME, Byington RP, Goff DC Jr, Bigger JT, Buse JB, et al. Effects of intensive glucose lowering in type 2 diabetes. N Engl J Med 2008;358(24):2545-59. 